\title{
Neurophenomenology and Intersubjectivity: An Interdisciplinary Approach
}

\section{Mirko Di Bernardo ${ }^{1}$}

Received: 27 February 2021 / Accepted: 15 August 2021 / Published online: 3 September 2021

(c) The Author(s) 2021

\begin{abstract}
The article aims to provide the main conceptual coordinates in order to fully understand the state of the art of the most recent research in the field of neurobiology of interpersonal experience. The main purpose of this work is to analyze, at an anthropological, phenomenological and epistemological level, how the fundamental characteristics of the recognition of otherness and intercorporeity among human beings contribute to changing the image of nature in the light of a possible new relationship between living bodies, neurophysiological systems and empathy. From this point of view, the hypothesis to investigate is that neurophenomenology, understood as a new evolutionary, multidimensional and autopoietic approach, is capable of probing the preconditions of the possible delineation of a phenomenology of intersubjectivity shaped by the neuroscientific turning point, represented by the discovery of mirror neurons. At this level, the neuroscientific data are interpreted according to a specific interdisciplinary perspective, thus trying to offer a possible unitary and integrated theoretical framework.
\end{abstract}

Keywords Otherness $\cdot$ Enaction $\cdot$ Intercorporeity $\cdot$ Neurosciences $\cdot$ Epistemology of complexity $\cdot$ Living body $\cdot$ Empathy

\section{Introduction}

How can phenomenology collaborate in the neuroscientific understanding of the biological foundations of intersubjectivity? And how can neurobiological evidence make the phenomenological theme of intercorporeity more solid? These are the salient questions that animate the present examination which aims to offer an interdisciplinary framework capable of revisiting the phenomenological concept of the living body in the light of the new scenarios opened up by the most recent neurophysiological studies on mirror neurons. These experimental researches provide a subpersonal description

Mirko Di Bernardo

mirko.di.bernardo@uniroma2.it

1 University of Rome "Tor Vergata", Rome, Italy 
of the human relational dimension, allowing today to integrate data from developmental psychology and infant research that previously had already highlighted the crucial importance of the relationship for the psycho-affective development of the child from the earliest stages of life (Beebe et al. 2005). Therefore, developmental psychology had already shown that the mind is born as a shared mind, highlighting the fact that the main object of interindividual relations of infants coincides with the affective behaviour of the other (Meltzoff 2007). Nevertheless, until not many years ago, the nervous mechanisms underlying the ability to understand the behaviour of others were little known. The discovery of mirror neurons in monkeys (Gallese and Goldman 1998) and the subsequent demonstration of mirroring mechanisms in the human brain revealed, for the first time, a neurophysiological mechanism capable of explaining many aspects of our ability to relate to others (Mukamel et al. 2010).

In particular, the present study, comparing in methodological terms the experimental aspects of the cognitive sciences with the holistic approach of the spiritual sciences, intends to offer a theoretical synthesis capable of objectively integrating the level of first-person description with that of the third person, also rooting this mutual completion in the phenomenological concept of the living body. Here the autopoietic and historical aspects of biological life, in constant evolution and coevolution, are in deep osmosis with the phenomenological aspects of conscious life which are fundamental for the understanding of how conscious subjectivity unfolds in relation to otherness; at this level of analysis neuroscience finds in the body its own inexhaustible material for empirical study.

The concept of autopoiesis elaborated by Maturana and Varela is therefore able to merge together, in an admirable way, themes and methods coming from the most disparate sciences (Maturana and Varela 1980) according to a new systemic and integrated approach called neurophenomenology. In agreement with South American scholars, therefore, it is possible to arrive at the definition of an autopoietic unit as a system capable of self-maintaining due to a process of self-generation of components that is triggered by an intricate plot guided by a specific internal teleology of interactions and molecular recognition. This doctrine still offers today an adequate holistic anchorage for the generalization of the analysis of the relationship between life and cognition in the development of subjectivity (Bitbol and Luisi 2015). Therefore, enaction and reflexivity appear as two sides of the same coin, i.e. as two complementary aspects of the creative and organismic dimension of every biological system. If, in fact, enaction is understood as that process of extrapolation of meanings and of a world in the course of a sense-motor interaction with the environment and with others, reflexivity represents, on the other hand, the inseparable dimension of the living agent from the world with which it is united in a relationship of mutual specification and co-emergence.

\section{Mirror Neurons, Motor Intentionality and Enaction}

The mirror neurons (particular visual-motor neurons detected in the macaque, through measurement with micro electrodes) would be the result of a complex intermodal learning process, i.e. dependent on different sensory modalities. In 
this sense, the motor system would make us able to understand in a pre-discursive way the meaning of other people's gestures we observe. This approach has prepared the ground for the formulation of hypotheses suggesting the unity of the motor sense experience which has been substantially based on the inseparability of the understanding of the meaning of other people's gestures from the possibility of representing them in one's own motor vocabulary (Fogassi et al. 2005).

Moreover, mirror neurons are considered by most scientists as the neurophysiological basis of "empathic mirroring" as an automatic and not inferential process. This allows the subject to relate to the other. In summary, the discovery of mirror neurons has suggested the "inscription" of intercorporeity within neuronal processes, although motor resonance is not sufficient to explain the onset of empathy, but it is crucially involved.

The discovery of the Parma school (Rizzolatti and Sinigaglia 2016) on how some neuronal architectures of the premotor cortex are involved in perceptual as well as motor functions gives phenomenological reflection an extra analytical chance: to treat the pre-reflexive and pre-linguistic knowledge proper to the living body by assuming the mutual implication of sensitivity and movement (Gallese 2007).

The understanding of the role and functioning of mirror neurons imposes then a remarkable change of scientific paradigm, because it obliges the inclusion of the motor aspect in the cognition process: acting is already thinking and action is at the basis of learning; but let's go step by step.

Mirror neurons are defined as the class of nerve cells present in the F5 area of the premotor cortex whose activation is related to visual-motor and/or audio-motor tasks: their peculiarity lies in the fact that they are selectively activated both during the execution of a transitive action and during the observation of the same type of action (Rizzolatti et al. 1996; Gallese et al. 2004). The visual signal, in synthesis, is sent to the premotor cortex that prefigures the action (i.e. creates the motor scheme) as a potential act even if this will not occur or has not yet occurred. Another interesting aspect of this selective activation is that it disregards the subject who is observed while performing the action, but depends solely on the type of action performed on the basis of the intentional meaning that characterizes its practical purpose. The excitement of mirror neurons, in fact, is not stimulated only by visual input but by a "vocabulary of motor acts" (Rizzolatti and Sinigaglia 2016: p. 763) that the subject recognizes as endowed with meaning and belonging to his/her own experience. The wider this "vocabulary" is, the more the subject is able to learn (Rizzolatti and Sinigaglia 2006: pp. 44-48, my translation).

"The seeing that guides the hand is also, if not above all, a seeing with the hand, with respect to which the perceived object appears immediately codified as a determined set of hypotheses of action. The congruence between the visual and motor selectivity of the neurons of the F5 and AIP areas shows, in fact, how the potential acts evoked predeline [...] a sense of the object 'seen' that contributes to determining it as this or that graspable with this or that grip, thus giving it a 'significant value' that it could not otherwise have" (p. 49).

Many experiments have underlined the importance of previously acquired motor skills and the familiarity with them in the discrimination and recognition of 
intentionally characterized motor actions (Bonini et al. 2009). Mirror neurons do not react to the stimulus as such, but to its meaning.

The observation of other people's actions triggers a sudden activation of motor areas which, through pre-conscious cognitive mechanisms, make it possible to decipher the meaning of the motor events observed. Always within this conceptual framework, neuroscientists speak of a "common representational scheme", shared by several subjects and specific for certain types of actions; this idea is flanked by that of "multimodal coding" which describes the mechanism by which each visual experience is a potential motor performance (Rizzolatti and Sinigaglia 2016: p. 764).

The enthusiasm for these discoveries and for the potential that could have resulted from them led, for example, neuroscientist Ramachandran (2012) to argue that mirror neurons were to psychology what DNA was to biology.

Although mirror neurons seem to play a role in the imitation of simple and purposeful actions, today not all scholars agree with the thesis supported by the Parma school. In fact, some scholars believe that it has not yet been clearly demonstrated that mirror neurons underlie action understanding (Hickok 2012, 2014; Watson and Bird 2019). From this perspective, reproducing a simple action at the neural level is not equivalent to empathizing with the complex psychological states of the other person. The exclusive functionality of mirror neurons would not be sufficient to explain imitation, since other neural systems are involved and, moreover, lesioning in the areas of their localization does not result in the inability to recognize and understand the actions of others, as occurs in patients with fronto-parietal lesions (Taylor 2016).

According to Hickok (2014) and other scholars (Cook et al. 2014), not only is it time to abandon the mirror neuron hypothesis as a system for understanding action, but even the specific role attributed to mirror neurons in social-cognitive processes and their very presence in humans must be questioned. These arguments have provoked a heated epistemological dispute with scholars of the Parma school with respect to the objectivity of the approach they use and the way in which hypotheses are formulated up to and including experimentation (Taylor 2016).

Despite the counter arguments mentioned above, the theses put forward by the Parma school still enjoy wide international recognition. Beyond the different perspectives involved, we can not help but notice that for the majority of scholars mirror neurons must still be investigated within a broader context where their functions are expressed within and by virtue of complex functional systems. The contribution of mirror neurons is probably realized at the lowest perceptual level, for example in the discrimination of a body movement, rather than in the reading of the intentions of the person performing that movement. Moreover, these are processes that do not remain unchanging from birth, but acquire and modify mirror properties through sense-motor learning (Fogassi et al. 2005).

These are the conclusions present in the review recently conducted by Heyes and Catmur (2021) of all scientific studies published on mirror neurons over the past decade. The scholars list the state of the evidence with respect to the various processes attributed to mirror neurons. With respect to understanding the actions of others, the various studies conducted with functional magnetic resonance imaging, brain stimulation, and on patients with lesions in the affected areas lead to the 
conclusion that mirror neurons are implicated in low-level processing of observed actions, such as discrimination and recognition of the movement and type of grasp of an object, while there is no evidence of their involvement in high-level processes such as inferring the intentions of those performing the observed actions. There is no definitive evidence for a role of mirror neurons in spoken language, but there is evidence for an involvement of the motor system, including premotor areas of mirror neurons and motor cortex, in language discrimination under perceptually noisy conditions.

With respect to imitation, there is strong evidence for an increased response of mirror neuron areas during the reproduction of observed movements. Finally, for autism, the complexity of studies has attempted but failed to demonstrate that a dysfunction of mirror neurons can be traced in its behavioral manifestations.

According to Heyes and Catmur (2021), only if they are studied in the context of a functional system can mirror neurons help explain complex processes such as the categorization of body movements, some aspects of language perception, and the neurological basis of imitation. Although on the relationship between mirror neurons and intentionality the Parma school has a different position than the arguments put forward by Heyes and Catmur, we cannot help but notice that regardless of the different perspectives outlined experimental research on mirror neurons have allowed us to revisit philosophical and phenomenological insights of the twentieth century able to hold together at the theoretical level the methodological reductionism and the holistic approach in order to understand in a rigorous way the totality or semantic unity of the processes at stake. In other words, it is necessary to find new tools for the comprehension of the complexity of the whole orchestra without having to dwell only on the contribution of individuals (Sarti et al. 2019).

The empirical results of the studies on mirror neurons reveal the very close relationship existing between perceptive, cognitive and motor processes, giving reason to the brilliant intuitions had in the last century by Merleau-Ponty, who thematized the relationship of the subject with the world. In this perspective he expressed himself in this way: "The organism, in order to exist, must encounter a certain number of physical and chemical agents around it; but it is precisely the organism, according to the nature of its receptors, according to the thresholds of its nerve centres, according to the movements of its organs, that chooses in the physical world the stimulus to which it will be sensitive" (Merleau-Ponty 1945: p. 316, my translation).

Already in the very early 1990s Varela had hypothesized an overlap between sensory and motor processes; hypothesis resulting from an enactive approach to perception considered not as something that happens inside us but as something we do (Varela et al. 1991) and in this regard Varela makes clear that cognition is enaction: a history of structural coupling that produces (enacts) a world. There are no more symbolic, sub-symbolic planes and manipulations, but a creation of meaning that occurs spontaneously as a consequence of the structure of living beings and their relationship with the world (Maturana and Varela 1980).

The motor sense aspect of corporeity, therefore, postulated first by the French phenomenologist and then by the enactive approach, is having more and more resonance within cognitive studies. To date it is clear that our body structure and our motor sense abilities are at the basis of the ability to understand others (De Caro and 
Putnam 2020) and therefore deeply connected in genealogical terms with the development of the sense of self and the emergence of the mind.

\section{Integration, sense of self and intersubjective experience}

The most recent studies on the relationships between brain structures and functions continuously provide new and increasingly accurate information on the mechanisms by which experiences influence human mental processes (Kandel 2019; Varela 1997; Jablonka and Lamb 2015). In the enactive perspective, the mind in essence should no longer be understood in terms of structure but as a dynamic process emerging from the activities of the brain whose structures and functions are directly influenced by interpersonal experiences (Siegel 2006). Specifically, according to Siegel's theory of neural integration (2018), the mind develops from processes that regulate flows of energy and information within the brain and between different brains. Therefore, the concept of the mind as an entity needs revision. The mind is not a thing or an object located in the body or space but a rope used to circumscribe many different psychological processes, mental phenomena and personal experiences, although often connected. The time has passed when we could talk about the mind or brain and their causal interactions; today we are dealing with a multiplicity of brain-mental phenomena and their relationships. The multiplicity of mental processes is usually referred to as the mind and functions at a higher level of biological organization than the brain (Varela and Depraz 2005). In turn, the activities of the mind lead to physiological brain changes, which can result in the expression of different genes (Siegel 1999). The subjective aspect that would characterize the perception of environmental inputs is due to the fact that the external environment is perceived by highly specialized deep structures through which stimuli and stresses reach a central structure to be processed, selected and stored so that energy and information are used for specific purposes. Environmental perception thus becomes a subjective experience that allows the living being to filter and adapt the mass of information and make it usable for both elementary and more sophisticated processes (Siegel 2018).

Starting from this complex interweaving, Siegel, in deep dialogue with Varela and in accordance with the enactive approach, considers the brain as a dynamic system formed by neural networks that can be activated in an infinite number of patterns and "neural profiles" and that can remember or learn from past experiences increasing the probability of activation of certain different excitation patterns (Siegel 1999: p. 24). This is what the scholar defines as "experience-dependent brain development", i.e., a development that strongly characterizes the first years of life and that lasts throughout the whole of existence, influencing not only the moments of memorization and learning but also those of recovery and use of cognitive-relational skills: remembering is the result of the construction of a new neuronal excitation profile, which presents characteristics typical of the initial engramma but also elements of memory derived from other experiences, and which is influenced by the context and the state of mind in which we find ourselves in the present. The processes that give "value" to human experiences are also differentiated, i.e., the increase in neuronal excitability and activation, the increase in neuronal plasticity and the induction of 
the creation of new synaptic connections, as well as the creation of new circuits connecting different brain areas (Siegel 2006). Through the regulation of internal and external factors the system of the mind evolves with the emergence of a series of states of the Self that possess their own cohesion and continuity (Varela 1997). As a non-linear system, the mind is also capable of rapidly and suddenly changing these constraints, with the activation of distinct and discontinuous states of the Self: the creation of a stable overall coherence from these different states is one of the central objectives of emotional development and self-regulatory processes (Siegel 2018).

At all times from the infinite range of possible brain activities emerges a state of mind that groups together a coherent set of processes aimed at achieving specific goals and the integration of these processes is mediated by emotions. Emotions constitute "organizational and integrative processes" that play a central role in coordinating different activities of the mind, giving stimulus specific meanings and precise motivational directions (Costantini et al. 2019). The co-construction of narratives is thus seen as an opportunity for the likely involvement of a resonance of processes mediated by the two cerebral hemispheres and as a result of an interhemispheric resonance within the minds of the subjects in relation to each other. They are mostly "emotional memories", preserved more and better than many other moments just because they bring with them a particular emotion, but always and however intense and enveloping; it is precisely these memories that, once recalled by the temporal sequence of the narration, contribute to the construction of the sense of self (Rizzolatti and Sinigaglia 2019). The recomposition of the synchronic and diachronic continuity of the past reawakened by emotions can hardly, in fact, be relative to the routine experiences of everyday life, but it is given with greater probability by the exceptionality of some crucial moments of which one has been protagonist and which persist in one's memory giving continuity to one's personal existence. The integration of the Self, therefore, in agreement with Siegel, is a process that creates coherence through autopoietic processes linked to interaction with other Selves. It is a non-linear process that goes through regressive and progressive moments, it is the result of processes of organization, disorganization and reorganization. Integration processes allow the establishment of a sense of congruence and unity within flexible patterns in energy and information flows: "integration" is therefore defined as the set of processes that create coherence within the mind, where "coherence" means the state of the "system in which functions of different nature are connected and activated over time" (Siegel 1999: p. 322). These processes are interpreted, in neurophenomenological terms, as states of the system that maximize complexity by achieving greater stability. In this way, integration defines the Self since in its movement of increasing complexity the system of the mind brings together distinct processes in unitary and cohesive states. From here, "optimal experiences" can be considered those characterized by a sense of "union" in which the individual feels part of a process that goes beyond the limits of the Self. Experiences of this kind provide empirical support to the idea of the existence of a relationship between integrative processes and experiences of "union" or "flow". Personal integration processes can be reflected in a flow of collaborative communication that moves in a balanced way between continuity, familiarity and predictability on the one hand and flexibility, novelty and uncertainty on the other. When these interpersonal communication 
processes are fully activated, when the union of minds is "at full capacity", a sense of vitality, immediacy and authenticity is created that can be extremely involving and stimulating. It is in these particularly intense moments, in these states of dyadic resonance, that we truly appreciate how relationships with others can nourish and heal our minds (Siegel 2006). The approach to the study of the relationships between corporeity, development of the sense of self and intersubjectivity seems, therefore, to bring with it fixed points and shadow zones; that is, it seems to contain elements that can be considered and observed directly and that provide the certain basis of this intricate relationship and of the hierarchical and informational processes that represent complex variables, subtle and without generalizability, elusive through recourse to a direct analysis and elusive from any form of eliminativist reductionism.

\section{Intersubjectivity, Empathy and Embodied Simulation}

The mind, at all stages of life and development, can modify the structures, functions and neuro-anatomical connections of the brain. This constant plasticity is in various ways connected to the radical relational essence of the mind which continuously builds structural couplings with the environmental system (Petitot et al. 1999), that is, new combinations between the things of the world which give rise to an incessant psychic dynamism. The correlated, under a neuronal profile, of the relational essence of man, widely reported by epistemological-clinical literature, is represented by the neuron-mirror. This seems to suggest that mirror neurons represent the necessary, but not sufficient, pre-requisite for empathic behaviour among people, and vice versa that the latter is linked, in its reality, to experiences. The "mechanism-system" neuron-mirror, in fact, does not automatically correspond to feeling empathy for the Other; rather this possibility, and more generally the countless ways of feeling the Other, have to do also, and above all, with the relational quality that binds people, from our point of view, with their subjectively understood identity. Conversely, in order to establish full and effective emotional communication between two people, it is necessary for each of the people involved to let their own state of mind be influenced by that of the other, so that they "feel" it and tune in to it.

This is the origin of the axiom that underpins this work: the relationship-or rather the intentionality in the neurophenomenological sense (Petitot et al. 1999) - is the basis of every living body. The neuron-mirror system, in fact, seems to represent to a large extent the neuro-biological correlate of the assumptions of the theory of intentionality as divided in some ways by the Husserl of passive syntheses and in part, albeit with different nuances, by the neurophenomenology of Varela and Shear (1999) and Petitot (2013) which instead extends the notion of intentionality also to unconscious life; in any case, in both approaches, this theory has highlighted in a profound way the relational essence of human identity itself. Particularly interesting is the Husserlian concept of Paarung, according to which the other is understood thanks to a primitive holistic coupling process. In my opinion it seems a good starting point to frame the implicit dimension of the intersubjective capacity to transfer meanings from one person to another using the body as a vehicle for this transfer, both from the point of view of the expression of meaning and from that of the 
capacity to decode it when we are spectators. In phenomenology, the crucial dimension of intersubjectivity in the construction of subjectivity is emphasized; this does not mean that subjectivity does not have a fundamental dimension of its own. They are two complementary dimensions, but if we leave intersubjectivity out, we risk arriving at the image of the mind and psychism that has prevailed and characterized the cognitive sciences over the last fifty years, the one that reifies the body.

Body, on the other hand, is the pre-logical and pre-predictive origin of our ability to understand, "flesh of the world", as Merleau-Ponty (1945) writes, underlining the centrality of empathy in the experience of the world. Facing the phenomenon of empathy, these searches do not refer to a series of behaviors or functions, but to experience, to what Edith Stein meant when she spoke of the "presentification of the experience of others". This experience immediately grasp the humanity of the other through an intentional act that goes beyond observation or cognition, as "unique and irreducible form of intentional experience" (Thompson 2001: p. 16). In the light of all this, therefore, Varela, putting neurophysiological studies in close relation with the analysis of phenomenology, studies empathy not thinking about a feeling or a particular kind of understanding, but about the fundamental form of our "being with others", about "being structurally designed to have relations with our congeners, with individuals of the same species". One of the most significant discoveries of the neurophenomenological movement is that the investigation of the structure of human experience inevitably leads to a turning point in the consideration of the inextricable link that unites, in an empathic mesh, my consciousness to that of others and to the phenomenal world (Varela and Shear 1999: p. 46).

Just as for Husserl the recognition of the other passes through the ambiguity of the body itself, ${ }^{1}$ so Varela entrusts the embodiment with the attempt to make intelligible the fact that an entity can have both the characteristic properties of matter and the characteristic properties of the mental, despite the apparent heterogeneity between them.

And, in the same way as Husserl, he finds in this "lived duality" the reason for the recognition of the other: if the body is an "ontological machine", an ambiguous unity of mechanism and transcendence, "one must abandon the notion of an interior as a logical system and an exterior as a source of information" and admit the coexistence of many "possible worlds". And here, Varela points out, "we are not talking about philosophy, we are talking about a logic of research" (Varela 1990: p. 46, my translation). Therefore, phenomenological reflection arises even before the study of

\footnotetext{
1 The presence of the others is connected, in Husserlian reflection, to the objective and bodily presence: I perceive the world not only as my world, but as a horizon inhabited by other "similar" presences to my presence. The exercise of the epochè reveals the presence as structurally "ambiguous", as "lived duality" between psychic and corporeal being. When I put in brackets everything I have learned about my conscience and my body, it reveals the paradox of human subjectivity which is both subject to the world and object in the world. This experience of "lived duality" is connoted by Husserl as "extraneous belonging" and "immanent transcendence". The structural non-coincidence with myself that I find in the experience of my body, in my temporal and possible determinations, in my not completely explicit presence, this "my own" otherness is, as Husserl says, primordial with respect to the constitution of any extraneous objectivity and makes me perceive the other as an "analogous stranger" (Husserl 1931, 1952).
} 
the mirror system and in many ways influences it. In the last of the Cartesian Meditations Husserl introduces the notion of Einfuihlung to account for the experience of the other: it is an original affectivity, a syn-pathein which is a "feeling together", not a theoretical or intellectual "seeing". Husserl therefore postulates an indirect intentionality that makes me com-present the other (Husserl 1931). Every time one interacts with others, a shared empathic space is created which implies a spontaneous mirroring: "the understanding of other people's emotional states depends on a mirror mechanism able to codify sensory experience directly in emotional terms [...] such understanding is the necessary prerequisite for the empathic behaviour that underlies a large part of our interindividual relations" (Rizzolatti and Sinigaglia 2006: p. 177). The mirror mechanism allows us to pre-reflectly understand the emotional state of others, integrating visceral and emotional components that would otherwise be absent in the understanding with top-down cognitive modes. The neuroscientist Gallese concentrated much of his research work on the phenomenological characterization of the results obtained in mirror neuron experiments, thus arriving at a new model from the point of view of the interpretation of intersubjectivity and constitutive empathy: perception is not only the result of motor patterns, but together with movements it is also the result of the network of skills and attitudes developed in the context of a structural interpersonal interaction (Gallese 2006b). Moreover, Gallese developed the intersubjective role of this class of neurons by elaborating the theory of embodied motor simulation which testifies a deep link between the observer and the actress: for the first time, a neural mechanism has been identified which allows a direct translation between the sensory (visual and auditory) description of a motor act and its execution. Perceiving an action as an action, and not simply as a sequence of movements, and therefore understanding its meaning for us, is tantamount to simulating it internally, that is, it is tantamount to activating its motor programme even in the absence of the factual execution of that same action (Gallese 2020). This means that the observer is able to understand the world of the other from within.

The first expedient one has to put oneself in the other's shoes and grasp his intentions is to transfer empathically into the concreteness of his experience, thus simulating his intentional state (Gallese and Lakoff 2005). The ability to empathize is the basis of our ability to grasp the intentions implicit in the gestures and expressions of others without having to infer them by inferential means. However, this transposition into the role of the other is possible because I possess a Leib, which is a condition of my seeing my own perceptions and actions in the other. However, embodied simulation does not reproduce within our mind what is happening in the other's mind (from a mind reading point of view) (Gallese and Godman 1998), but allows us to tune in first person with the experience he has experienced because it does not presuppose an analytical-inferential process, but attempts to gain an empathic knowledge of the other's experience (Gallese et al. 2007).

The "intentional consonance" (Gallese 2006b) with the other is always a relationship of meaning and thanks to it the alter does not present himself to me as a representational system but becomes a person like me.

Starting from the mirror functions one could thus try to understand what are the natural and physiological causes of this direct sharing of experience. They tell of 
a similarity between the cortical processes of different individuals, thus suggesting "that the root of subjectivity is an original intersubjectivity" (Manganaro 2012: p. 26, my translation).

\section{The Neurophenomenological Reduction}

Existential phenomenologists argue that the two most basic forms of intelligent behavior, learning and skillful action, can be described without recourse to representations of the mind or brain. This claim is expressed in two central notions in Merleau-Ponty's Phénoménologie de la perception (1945): the intentional arc and the tendency to achieve a maximal grasp. The intentional arc names the close connection between body and world, such that, when the active body acquires abilities, they are "stored" not as representations in the mind, but as dispositions to respond to the stresses of situations in the world. A phenomenology of skill acquisition confirms that, as expertise is acquired on the way, the acquired know-how is experienced as increasingly fine discriminations of situations coupled with the appropriate response to each. Maximum grasp names the body's tendency to refine its responses so as to approximate the current situation to an optimal gestalt. Thus, successful learning and action do not require propositional mental representations. Nor do they require semantically interpretable brain representations. Simulated neural networks show crucial structural features of the intentional arc, and the account of brain dynamics underlying perception and action according to some studies appears structurally isomorphic with Merleau-Ponty's report of the way an experienced agent is guided by the situation to move toward obtaining a maximal grasp (Dreyfus 2002).

Therefore, behavior should not be understood as simply an organism's response in terms of movement to an external stimulus. Rather, it reveals a wealth of data that exceeds its objectification and quantification. It shows itself as a unity that cannot be split between an interior inaccessible to observation and a measurable exterior. In this sense, Merleau-Ponty argues that it is not a material or even a psychic reality, but a structure that does not properly belong to the external world or to internal life (Merleau-Ponty 1942).

This definition is of great interest first of all because it gives an exact meaning to the term structure. Structure is here to be understood in the holistic sense of a unity that cannot be dissected into parts nor obtained by their recomposition or juxtaposition, and is therefore defined as "form" as a new category to be introduced into scientific observation. In the second place, the definition indicates the philosophical ground chosen by the French phenomenologist: the increasingly accurate description of an intermediate region between subject and object, between nature and culture, between consciousness and world, between nature and history, between determinism and freedom, which the philosophies preceding Husserlian phenomenology had precluded themselves, privileging each time one of the horns of the dilemma and defining their programs starting from this choice. The search for a third mediator element between the opposites is in the eyes of the phenomenologist the chance to relaunch philosophical and scientific thought. 
The disavowal of prejudices requires a reflexive exercise as a modification of the observer's attitude and gaze. The phenomenological attitude is obtained by putting gegebenheit in brackets, no longer thought of as natural, but as objects whose constitution must be questioned. (Merleau-Ponty 2002).

The epoche is the methodological precondition for the foundation of a scientific knowledge and a philosophy that is intended as a rigorous science, it is the search for the meaning of things before and beyond any supposed knowledge and already built on them. He specifies a way that leads from the methodological objectivism of the schools prior to Gestaltpsychologie to a "phenomenology of form" that founds, on new bases, theory and scientific experience. Starting from the objectified exteriority of experimental science (the behavior of organisms), it progressively recovers that interiority, that is, the sphere of consciousness which the same observational data require when they are interpreted in the light of a non-dogmatic psychology.

This approach is clear from the very way Merleau-Ponty approaches the problem of intersubjectivity. I can enter into a relationship with the other because it has always been here, it shares with me a common nature, which is the perceptive nature as an opening to the world; it is possible for me to rediscover each time my deep bond with the other in corporeity, in love, in the fungent life as a background that unites us (Merleau-Ponty 1942). The scientific discoveries on mirror neurons, neural correlates of empathy, fully confirm these phenomenological insights.

The possibility of empathizing and thus making effective the second empathic person who abandons his own beliefs, his own "here", to put himself in the other person's clothes (Varela et al. 1991) implies that the act of phenomenological reduction is not purely cognitive, but involves corporeality deep down: the power of the mind alone is not enough to make this experience effective if corporeality and affections do not make their contribution and are not thereby transformed and intensified (Depraz 2006: p. 105).

Mirror neurons, in fact, are not epistemic agents. "Neurons 'know' only the passage of ions through their membranes. Metallization needs a person, which we could define as a system of interconnection between brain and body that interacts in a situated way with a specific environment populated by other brain-body systems" (Gallese 2006a: p. 173, my translation). Therefore, the system of mirror neurons represents for human being the possibility to immediately establish a bridge between the observer and the actor, to determine, that is, a shared space of action, within which every act and every chain of acts, ours and others', appear immediately inscribed and understood, without requiring any explicit or deliberate "cognitive operation" (Rizzolatti and Sinigaglia 2016: p. 757).

Obviously, this is not a mystical fusion with the other, which would not be possible, since everyone is embodied in an one's own unsurpassable "be there", but a tension towards the other that leads us to share his experiences. This sharing, based on empathy, is made possible by the fact that both share the same experience in the first person. It is not a conceptually mediated operation but a deeply carnal act.

Unlike the Cartesian reduction, the phenomenological one relies precisely on the body and its properties to return to inhabit that original incarnated sensitivity, which we all share as incarnated subjects and which was subsequently covered by the stratification of clothes and habits not only ontogenetic, but above all phylogenetic. The 
"lived body" which is the centre of my present and living experience, is the "pivot of the world" (Merleau-Ponty 1945: p. 130) is the foundation of knowledge: a practical and a posteriori foundation, based on flesh and action. Neuroscience, by focusing on action, makes phenomenological descriptions concrete.

This corporeity is, of course, also the place of any empathic feeling that leads to the formation of a co-singularity: "My ego can be united with another ego (a You). Each ego is in contact with itself and coincides in a certain way with the ego with which it is confronted, the action of the one and the action of the other are not only separate actions running in parallel but form a single action since they are regulated on each other in a harmonious way and in mutual agreement. This unitary character can take several forms" (Manganaro 2012: pp. 120-121). It is in experiencing in the first person through a practice that involves in an essential way the "lived body" of the subject that we find the meeting place between the theoretical subject and the existential subject, between the descriptions in the third person and those in the first person. The neurophenomenological approach, supported by the enactive theory of the mind, is the first to consider first-person experience not as a simple epiphenomenal emergency but as a reality that has its own status and causality and that must be explained for what it is, without being reduced to the underlying plane that generates it (Depraz 2006). Moreover, the body is no longer investigated as the simple object of biology regulated by biochemical laws, but it is considered as the place of experience from which the intentional threads that connect us to each other and that allow us to act, to enact, to create a world and an ego (Voltolini 2013). Enaction, in fact, places the mind "in a body experienced with movement and sensitivity, in a biological evolutionary time, in a lived ecological space, in a process of production of meanings that is precisely the staging of all this, including consciousness; and under the scene there is no fixed and predetermined reality (Bertossa and Ferrari 2006).

In this perspective, every cognitive act manifests itself as an experience intrinsically connected to the body and as an immediate qualitative feeling, not theoretical but experienced.

\section{Concluding Remarks}

Phenomenological reflection digs to find the roots of intersubjectivity (all too often set aside by contemporary cognitive sciences) and in its relentless research provides technically useful equipment for conceptualizing and interpreting the functioning of mirror neurons.

The experimental investigations conducted by the Parma team invite us to reconsider the description of intercorporeity by phenomenologists such as Husserl and Merleau-Ponty and to practice phenomenology as a style of thought.

By focusing on the body as the centre of lived experience, it becomes a point of view on the world, "a centre of perspective" (Merleau-Ponty 1945: p.18) and can no longer be considered as a mechanism or a set of permanent sensations. In the same way, motility can no longer be considered only from a physiological point of view, but as an authentic experience lived by the embodied subject (Merleau-Ponty 1945). 
The rediscovery of the body implies the rediscovery of the perceived world in which I meet the other, animated by a consciousness that is foreign and transcendent to me: it is neither my idea nor my representation. I can enter into a relationship with the other because he shares with me a common nature, that is, the perceptive nature as an opening to the world and it is possible for me to rediscover each time my deep bond with the other in corporeity, in the life functioning as a background that unites us: the other is perceived as a "place" of experience.

Therefore, no inference or analogy is necessary to be able to meet the other; such an encounter initially occurs on a perceptive level; in the wake of Merleaupontian theories, Gallese postulates the primacy of perception also in the interpretation of behaviour: "the sense of others' gestures is not given, but understood, that is, recaptured by the action of the observer. [...] The discovery of mirror neurons offers an empirical basis to this conception of intersubjectivity seen as reciprocity and correlation between the self and another self which is in many ways simultaneously and primarily another self" (Gallese 2006a: p.159).

There is an original connection between experienced phenomena and expressiveness that underlies any interaction between subjects. "The body is eminently an expressive space" (Merleau-Ponty 1945: 201) because the bodily gesture is an extrinsication of meanings, passage from inside to outside and, at the same time, creation of a world to inhabit. The intentionality of movement takes place against the background of the given world, therefore in the concrete movement a background unfolds on which the movement acquires meaning. The gesture of the arm with which I make a sign to approach a friend, for example, presupposes an entire structuring of the world as a free space that is organized around my Leib, which projects meanings into the world through the gesture. The "motility as original intentionality" (p. 193), highlights the sense of behaviour, since this is inscribed within a linguistic-symbolic dimension coinciding with Umwelt's perceptive organization.

From this point of view, intersubjective perception becomes a direct, bodily and above all interactive mechanism: in the encounter with the other I am not a simple observer, but I respond in an "embodied" way; thus social interaction becomes synonymous with social cognition: a process in which body movements, facial expressions and contingent context become fundamental (Rizzolatti and Craighero 2004).

Corporeal scheme, intentionality and Leib represent a conceptual triad proper to a phenomenological reading of the theme of intersubjectivity, whose heuristic importance is clear to the discoverers of mirror neurons themselves. In the light of the latest neuroscientific discoveries, therefore, the subject could be described as an organism endowed with an innate sense of the bodily Self (pre-reflexive and precognitive), thanks to which it comes to a notion of self and otherness.

The discovery of mirror functions is only one example of how phenomenology and cognitive sciences can enrich each other. The investigation of the topic of intercorporeity cannot disregard deep philosophical speculations or detailed scientific investigations that have the merit of providing a "concrete" understanding of phenomenological descriptions. But this is also the challenge posed by the neurophysiologist Varela who "demands a re-learning and mastery of the phenomenological description skills of science" (Varela et al. 1991: p. 89). Varela's neurophenomenological investigation method is an extension of cognition theory as an enaction. He 
rejects any representationist conception that opposes an inaccessible interior to a measurable exterior. So, according to Varelian analytical horizon, clearly inspired by Merleau-Ponty's reflection, the body acquires an indisputable centrality: "The cognitive network is a network of interdependent bodily experiences, internal and external to the body; therefore, the neural correlates of an organism's experiences cannot be located in the brain, because they are decentralized in a network that is not only nervous, but of experienced relations between organism and environment" (Bertossa and Ferrari 2006: p. 250, my translation). Varela's intention is to bring life back into science, to stop that reductionist and objectivist drift that forgets the conscious subject and his experience in order to devote himself solely to experimental data and algorithmic procedures. It is the body that forges our givenness (Gegebenheit) in a dynamically open way to accept otherness, in relation to contingencies. The mirror system cannot be described simplistically as a mechanism of recognition of action, because it constitutes a way of interpreting the gestures of others within a specific context. To come into contact with the other means to tune in with another body that inhabits the same space as mine and is provided with a mind exactly like mine, but completely different because it is unique and unrepeatable. It is not difficult to understand why, from a phenomenological point of view, the neuroscientific explanation of the mirror mechanism is not considered exhaustive of this experiential and intersubjective richness. The problematic nature of the question goes beyond the formal description of what happens in the brain when we empathize; rather, it lies in the understanding of why we do it.

Ultimately, "a dialogue between neuroscience and phenomenology is not only desirable but also necessary and inevitable. Such a dialogue will be all the more fruitful the more efforts are made on both sides to penetrate each other's problems in a multidisciplinary way, trying - as far as possible - to develop a common language" (Gallese 2006a: p. 160).

Funding Open access funding provided by Università degli Studi di Roma Tor Vergata within the CRUICARE Agreement.

Open Access This article is licensed under a Creative Commons Attribution 4.0 International License, which permits use, sharing, adaptation, distribution and reproduction in any medium or format, as long as you give appropriate credit to the original author(s) and the source, provide a link to the Creative Commons licence, and indicate if changes were made. The images or other third party material in this article are included in the article's Creative Commons licence, unless indicated otherwise in a credit line to the material. If material is not included in the article's Creative Commons licence and your intended use is not permitted by statutory regulation or exceeds the permitted use, you will need to obtain permission directly from the copyright holder. To view a copy of this licence, visit http://creativecommons.org/licen ses/by/4.0/.

\section{References}

Beebe B, Knoblauch S, Rustin J, Sorter D (2005) Forms of intersubjectivity in infant research and adult treatment. Other press, New York 
Bertossa F, Ferrari R (2006) Meditazione di presenza mentale per le scienze cognitive, pratica del corpo e metodo in prima persona. In: Cappuccio M (ed) Neurofenomenologia. le scienze della mente e la sfida dell'esperienza cosciente. Mondadori, Milano, pp 271-292

Bitbol M, Luisi PL (2015) Autopoiesis with or without cognition: defining life at its edge. La Nuova Critica 65-66:51-72

Bonini L, Rozzi S, Ugolotti Serventi F et al. (2009) Ventral premotor and inferior parietal cortices make distinct contribution to action organization and intention understanding. Cereb Cortex 20(6):1372-1385

Cook R, Bird G, Catmur C, Press C, Heyes C (2014) Mirror neurons: from origin to function. Behav Brain Sci 37(2):177-192

Costantini M, Tommasi L, Sinigaglia C (2019) How action performance affects object perception. Exp Brain Res 237:1805-1810

De Caro M, Putnam H (2020) Free will and quantum mechanics. Monist 103:415-426

Depraz N (2006) Mettere al lavoro il metodo fenomenologico. In: Cappuccio M (ed) Neurofenomenologia. le scienze della mente e la sfida dell'esperienza cosciente. Mondadori, Milano, pp 249-270

Dreyfus HR (2002) Intelligence without representation - Merleau-Ponty's critique of mental representation: the relevance of phenomenology to scientific explanation. Phenomenol Cogn Sci 1(4):367-383

Fletcher-Watson S, Geoffrey Bird G (2019) Autism and empathy: what are the real links? Autism 24(1):3-6

Fogassi L, Ferrari PF, Gesierich B, e al, (2005) Parietal lobe: from action organization to intention understanding. Science 308(5722):662-667

Gallese V (2006) Corpo vivo, simulazione incarnata, intersoggettività. Una prospettiva neuro fenomenologica. In: Cappuccio M (ed) Neurofenomenologia. Le scienze della mente e la sfida dell'esperienza cosciente. Milano, Mondadori, pp 293-326

Gallese V (2006b) Intentional attunement: a neurophysiological perspective on social cognition. Brain Res Cog Brain Res 1079:15-24

Gallese V (2007) Dai neuroni specchio alla consonanza intenzionale. Meccanismi neurofisiologici dell'intersoggettività. Rivista Di Psicoanalisi LIII 1:197-208

Gallese V (2020) Brain, body, habit and the performative quality of aesthetics. In: Testa I, Caurana F (eds) Habits: pragmatist approaches from cognitive neuroscience to social science. Cambridge University Press, Cambridge, UK, pp 376-394

Gallese V, Goldman A (1998) Mirror neurons and the simulation theory of mindreading. Trends Cogn Sci 12:493-501

Gallese V, Lakoff G (2005) The brain's concepts: the role of the sensory-motor system in reason and language. Cogn Neuropsychol XXII:455-479

Gallese V, Keysers C, Rizzolatti G (2004) A unifying view of the basis of social cognition. Trends Cogn Sci 8:396-403

Gallese V, Eagle MN, Migone P (2007) Intentional attunement: mirror neurons and the neural underpinnings of interpersonal relations. J Am Psychoanal Assoc LV 1:131-175

Heyes C, Catmur C (2021) What happened to mirror neurons? Perspect Psychol Sci 9:1745691621990638

Hickok G (2012) Computational neuroanatomy of speech production. Nat Rev Neurosci 13(2):135-145

Hickok G (2014) The myth of mirror neurons: the real neuroscience of communication and cognition. Norton \& Company, New York

Husserl E (1952) Ideen II: Phänomenologische Untersuchungen zur Konstitution. Kluwer, Dordrecht

Husserl E (1931) Cartesianische Meditationen und Pariser Vorträge. Kluwer, Dordrecht (1950).

Jablonka E, Lamb MJ (2015) The inheritance of acquired epigenetic variations. Int J Epidemiol 44:1094-1103

Kandel E (2019) The disordered mind: what unusual brains tell us about ourselves. Farrar, Straus and Giroux, New York

Manganaro P (2012) Intersoggettività, intenzionalità, empatia. Fenomenologia e neuroscienze oggi. Agathos: Int Rev Humanities Soc Sci III 2:21-31

Maturana H, Varela F (1980) Autopoiesis and cognition: the realization of the living. 2nd edition. Boston Studies in the Philosophy of science, The Netherlands, Dordrecht.

Meltzoff AN (2007) Like me: a foundation for social cognition. Dev Sci 10(1):126-134

Merleau-Ponty M (1942) La structure du comportement. Presses Universitaires de France, Paris

Merleau-Ponty M (1945) Phénoménologie de la perception. Gallimard, Paris

Merleau-Ponty M (2002) Causeries 1948. Éditions Du Seul, Paris 
Mukamel R, Ekstrom AD, Kaplan J et al. (2010) Single-neuron responses in humans during execution and observation of actions. Curr Biol 20(8):750-756

Petitot J (2013) Neurogeometry of neural functional architectures. Chaos, Solitons Fractals 50:75-92

Petitot J, Varela FJ, Roy JM, Pachoud B (eds) (1999) Naturalizing phenomenology: issues in contemporary phenomenology and cognitive science. Stanford University Press, Stanford

Ramachandran V (2012) The tell-tale brain: unlocking the mystery of human nature. Windmill Books

Rizzolatti G, Craighero L (2004) The mirror neuron system. Ann Rev Neurosci 27:169

Rizzolatti G, Sinigaglia C (2006) So quel che fai. Il cervello che agisce e i neuroni specchio. Raffaello Cortina Editore, Milano

Rizzolatti G, Sinigaglia C (2016) The mirror mechanism: a basic principle of brain function. Nat Rev Neurosci 17(12):757-765

Rizzolatti G, Sinigaglia C (2019) Specchi nel cervello. Come comprendiamo gli altri dall'interno. Raffaello Cortina, Milano

Rizzolatti G, Fadiga L, Gallese V, Fogassi L (1996) Premotor cortex and the recognition of motor actions. Cog Brain Res 3:131-141

Sarti A, Citti G, Piotrowski D (2019) Differential heterogenesis and the emergence of semiotic function. Semiotica 230:1-34

Siegel DJ (1999) The developing mind. Guilford Press, New York

Siegel DJ (2006) An interpersonal neurobiology approach to psychotherapy". Psychiatr Ann 36(4):248-256

Siegel DJ (2018) Aware: the science and practice of presence. TarcherPerigee, New York

Taylor JM (2016) Mirror neurons after a quarter century: new light, new cracks. https://sitn.hms.harvard. edu/flash/2016/mirror-neurons-quarter-century-new-light-new-cracks/. Cited 25 July 2021.

Thompson E (2001) Empathy and consciousness. In: Thompson E (ed) Between ourselves. Imprinting Academic, Thoverton

Varela FJ (1990) Il corpo come macchina ontologica. In: Ceruti M, Preta L (eds) Che Cos'è la conoscenza? Laterza, Roma

Varela FJ (1997) The naturalization of phenomenology as the transcendence of nature: searching for generative mutual constraints. Alter: Revue de Phénoménologie 5:355-385

Varela FJ, Depraz N (2005) At the source of time: Valence and the constitutional dynamics of affect. J Conscious Stud 12(8-10):61-81

Varela FJ, Shear J (1999) First person accounts: why, what and how. In: Varela FJ, Shear J (eds) The view from within. Imprinting Academic, Bowling Green

Varela F, Thompson E, Rosch E (1991) The embodied mind. Cognitive Science and Human Experience. The MIT press, Cambridge, London, England

Voltolini A (2013) The mark of the mental. Phenomenology and Mind 4:124-136

Publisher's Note Springer Nature remains neutral with regard to jurisdictional claims in published maps and institutional affiliations. 